\title{
Transcriptome Profiling of Louisiana iris Root and Identification of Genes Involved in Lead-Stress Response
}

\author{
Songqing Tian ${ }^{1,2, \dagger}$, Chunsun Gu ${ }^{1,+}$, Liangqin Liu ${ }^{3,+}$, Xudong Zhu ${ }^{1,2}$, Yanhai Zhao ${ }^{1}$ and \\ Suzhen Huang ${ }^{1, *}$ \\ Received: 6 June 2015; Accepted: 11 November 2015; Published: 25 November 2015 \\ Academic Editor: Eleftherios P. Eleftheriou \\ 1 Institute of Botany, Jiangsu Province and Chinese Academy of Science, Nanjing 210014, China; \\ 2012204030@njau.edu.cn (S.T.); chunsungu@cnbg.net (C.G.); 2010204026@njau.edu.cn (X.Z.); \\ 2014216028@njau.edu.cn (Y.Z.) \\ 2 Suzhou Polytechnical Institute of Agriculture, Suzhou 215008, China \\ 3 College of Horticulture, Nanjing Agricultural University, Nanjing 210014, China; 2013104113@njau.edu.cn \\ * Correspondence: hsz1959@cnbg.net; Tel./Fax: +86-25-8434-7097 \\ $\dagger$ These authors contributed equally to this work.
}

\begin{abstract}
Louisiana iris is tolerant to and accumulates the heavy metal lead $(\mathrm{Pb})$. However, there is limited knowledge of the molecular mechanisms behind this feature. We describe the transcriptome of Louisiana iris using Illumina sequencing technology. The root transcriptome of Louisiana iris under control and $\mathrm{Pb}$-stress conditions was sequenced. Overall, 525,498 transcripts representing 313,958 unigenes were assembled using the clean raw reads. Among them, 43,015 unigenes were annotated and their functions classified using the euKaryotic Orthologous Groups (KOG) database. They were divided into 25 molecular families. In the Gene Ontology (GO) database, 50,174 unigenes were categorized into three GO trees (molecular function, cellular component and biological process). After analysis of differentially expressed genes, some $\mathrm{Pb}$-stress-related genes were selected, including biosynthesis genes of chelating compounds, metal transporters, transcription factors and antioxidant-related genes. This study not only lays a foundation for further studies on differential genes under $\mathrm{Pb}$ stress, but also facilitates the molecular breeding of Louisiana iris.
\end{abstract}

Keywords: Iris; Lead; transcriptome; RT-qPCR

\section{Introduction}

The contamination of water by toxic heavy metals can occur naturally during soil erosion and flooding or anthropogenically by automobile emissions of leaded gasoline, emissions from industrial factories of coal combustion, smelting and cement production, agrochemicals, insecticides and herbicides [1,2]. Lead $(\mathrm{Pb})$ is a toxic heavy metal. The contamination of lakes, rivers, domestic waters and other water sources by $\mathrm{Pb}$ may lead to ecotoxicological problems in plants and animals, as well as damage to human health [3]. Plants could be effective heavy metal biological monitors, remediating contamination through rhizofiltration, phytostabilization or phytoextraction [4]. Therefore, identifying $\mathrm{Pb}$ hyperaccumulator plants, and the study of $\mathrm{Pb}$ absorption, transport and tolerance mechanisms in such plants, is very important.

Louisiana iris is an ornamental water plant, having originated in the marshes and swamps of the Gulf Coast States in the USA. Their natural habitat is comprised of wet, boggy areas that flood during the winter and spring [5]. New Louisiana iris cultivars grow well in various environmental uplands 
and wetlands, and are the most colorful of all of the Iris groups, making it a popular landscape plant. I. hexagona is one of its parents, and the I. hexagona population has become exposed to salt stress for more than 2000 years in southern Louisiana [6].

In recent years, RNA deep-sequencing (RNA-seq) has been used on several plants [7], including soybean [8], maize [9], cotton [10], chickpea [11], Chinese cabbage [12], potato [13], and Ammopiptanthus mongolicus [14]. It is a powerful method to screen for genes under biotic and abiotic stress conditions. Moreover, gene regulatory networks can be determined by RNA-seq. Some RNA-seq analyses of responses to Pb stress in plants have been reported. In the radish root, many differentially expressed genes (DEGs), which participated in defense and the detoxification of $\mathrm{Pb}$, were identified [15]. In response to $\mathrm{Pb}$ treatments, the transcriptional profiles of over 1310 genes in common stress responses or different biological pathways were investigated in Arabidopsis thaliana [16]. These studies indicated that plants have formed a complete response and defense system through a series of regulatory genes in response to $\mathrm{Pb}$ stress.

In previous studies, I. tectorum, I. lactea var. chinesis and I. halophila were found to be resistant to heavy metals [17-19]. Louisiana iris was found to be tolerant to and accumulate $\mathrm{Pb}$ in our physiological studies [20]. In Iris research, the transcriptomes of floral and young leaf tissue from I. fulva have been described [5]. However, there are no reports of genetic or genomic information for Louisiana iris. In our study, we used Illumina sequencing technology to facilitate the understanding of $\mathrm{Pb}$ tolerance in Louisiana iris at a molecular regulatory level.

\section{Results and Discussion}

\subsection{Sequencing and Reads Assembly}

When plants are under heavy metal stress, there may be an intense metabolism modulation by $24 \mathrm{~h}[15,20]$. Thus, a $24-\mathrm{h}$ time course of Pb stress was used to characterize the Pb-responsive genes in our study. To obtain a global overview of the Louisiana iris gene expression profile under $\mathrm{Pb}$-stress conditions, cDNAs from roots of control and $\mathrm{Pb}$ stressed Louisiana iris were sequenced using the Illumina HiSeq ${ }^{\mathrm{TM}} 2000$ platform. We obtained approximately 71 million raw reads from the $200 \mathrm{mg} / \mathrm{L}^{-1} \mathrm{~Pb}$-treated sample and 80 million raw reads from the control sample, and we removed low-complexity, low-quality and repeat reads. After strict quality checks and the cleaning of data, we had more than 128 million valid reads containing more than $12.0 \mathrm{G}$ of nucleotides. The average read size and read valid ratio were $93.84 \mathrm{bp}$ and $85.32 \%$, respectively. After assembly, adaptor tags and repeat reads were filtered out, producing 525,498 transcripts, and the mean transcript size was $726 \mathrm{bp}$. After clustering using chrysalis clusters, the lengths of the max contig, min contig, whole dataset, average contig and N50 were 15,986, 205, 156,000,000, 497 and 572 bp, respectively, in 313,958 unigenes (Table 1). The length distribution of the assembled unigenes indicated that 239,396 (76.25\%) unigenes ranged from 201 to $500 \mathrm{bp}$ in length; 46,190 (14.71\%) unigenes ranged from 501 to $1000 \mathrm{bp}$ in length; 19,298 (6.15\%) unigenes ranged from 1001 to $2000 \mathrm{bp}$ in length; and 9074 (2.89\%) unigenes were more than $2000 \mathrm{bp}$ in length (Figure 1). During assembly, $7.42 \%$ of the unigene annotations matching genes in Phytophthora sojae, Tetrahymena thermophila, Albugo laibachii Nc14, Paramecium tetraurelia and Phytophthorain festans were found. Interestingly, many more unigenes matched to Phytophthora sojae than to others in "non-plant" organisms. The diseases caused by Phytophthora in Iris occurred from the early growing season until the flowering stage [21]. The Iris plant used in this experiment may have been infected by Phytophthora. The disease cannot be phenotypically detected by the naked eye. This may be why a significant proportion of the unigenes were annotated as Phytophthora sojae. Fortunately, this result could also help explain Pb-stress biology and is therefore still meaningful to our study. 
Table 1. Overview of the sequencing and assembly.

\begin{tabular}{cc}
\hline Items & Number \\
\hline Total unigenes & 313,958 \\
Max contig length (bp) & 15,986 \\
Min contig length (bp) & 205 \\
Whole dataset length (bp) & $156,000,000$ \\
Average contig length (bp) & 497 \\
N50 & 572 \\
\hline
\end{tabular}

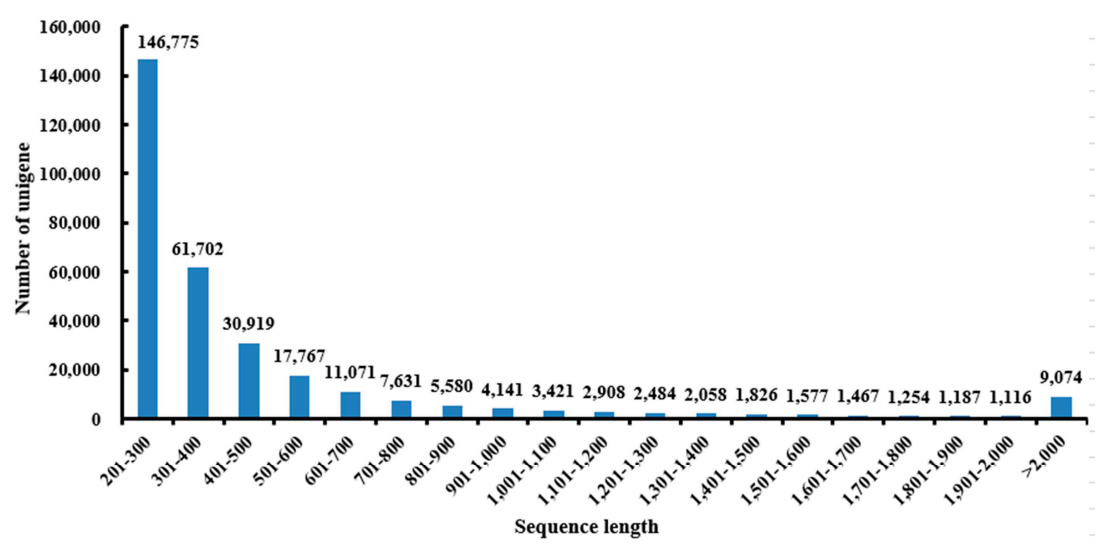

Figure 1. The length distribution of the assembled unigenes.

\subsection{Annotation of Unigenes}

All of the unigenes were aligned against protein databases of Nr, SWISS-PROT, TrEMBL, Conserved Domain Database (CDD), Protein Families Database of Alignments and Hidden Markov Models (PFAM) and Eukaryotic orthologous groups (KOG). The number of aligned unigenes was 89,738 (28.58\%) in Nr, 61,342 (19.54\%) in SWISS-PROT, 93,087 (29.65\%) in TrEMBL, 55,710 (17.74\%) in CDD, 80,756 (25.72\%) in PFAM and 43,015 (13.70\%) in KOG (Table 2). In the Nr database, the top 10 species annotated were Vitis vinifera (36.17\%), Oryza sativa Japonica Group (11.69\%), Populus trichocarpa (9.32\%), Ricinus communis (7.75\%), Sorghum bicolor $(6.99 \%)$, Brachypodium distachyon (6.57\%), Glycine max (6.15\%), Zea mays (5.41\%), Oryza sativa Indica Group (5.14\%) and Hordeum vulgare subsp. Vulgare (4.80\%) (Figure 2). In the KOG database, 43,015 unigenes were classified into 25 functional categories (Figure 3). In the Gene ontology (GO) database, 50,174 unigenes were classified into the three ontologies, biological process, cellular component and molecular function (Figure 4). For biological process, "cellular process" and "metabolic process" had the highest numbers of isotigs. For cellular component, "cell" and "cell part" had the highest numbers of isotigs. For molecular function, "binding" and "catalytic activity" had the highest numbers of isotigs (Figure 4).

Table 2. List of annotations.

\begin{tabular}{ccc}
\hline Annotation Database & Number of Annotations & Percent of Annotation (\%) \\
\hline Total unigene & 313,958 & - \\
Nr & 89,738 & $28.58 \%$ \\
SWISS-PROT & 61,342 & $19.54 \%$ \\
TrEMBL & 93,087 & $29.65 \%$ \\
CDD & 55,710 & $17.74 \%$ \\
PFAM & 80,756 & $25.72 \%$ \\
KOG & 43,015 & $13.70 \%$ \\
\hline
\end{tabular}

“-" means no percent of annotation. 


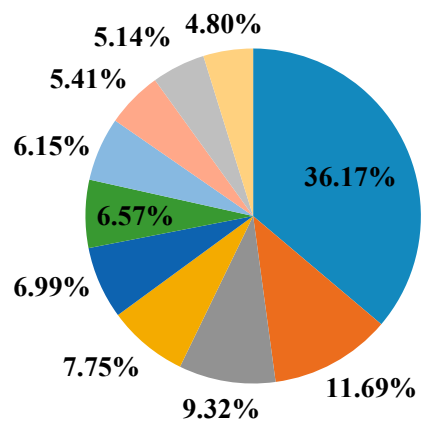

- Vitis vinifera
- Oryza sativa Japonica Group
- Populus trichocarpa
- Ricinus communis
- Sorghum bicolor
- Brachypodium distachyon
- Glycine max
- Zea mays
- Oryza sativa Indica Group
- Hordeum vulgare subsp. vulgare

Figure 2. The most represented species distribution.
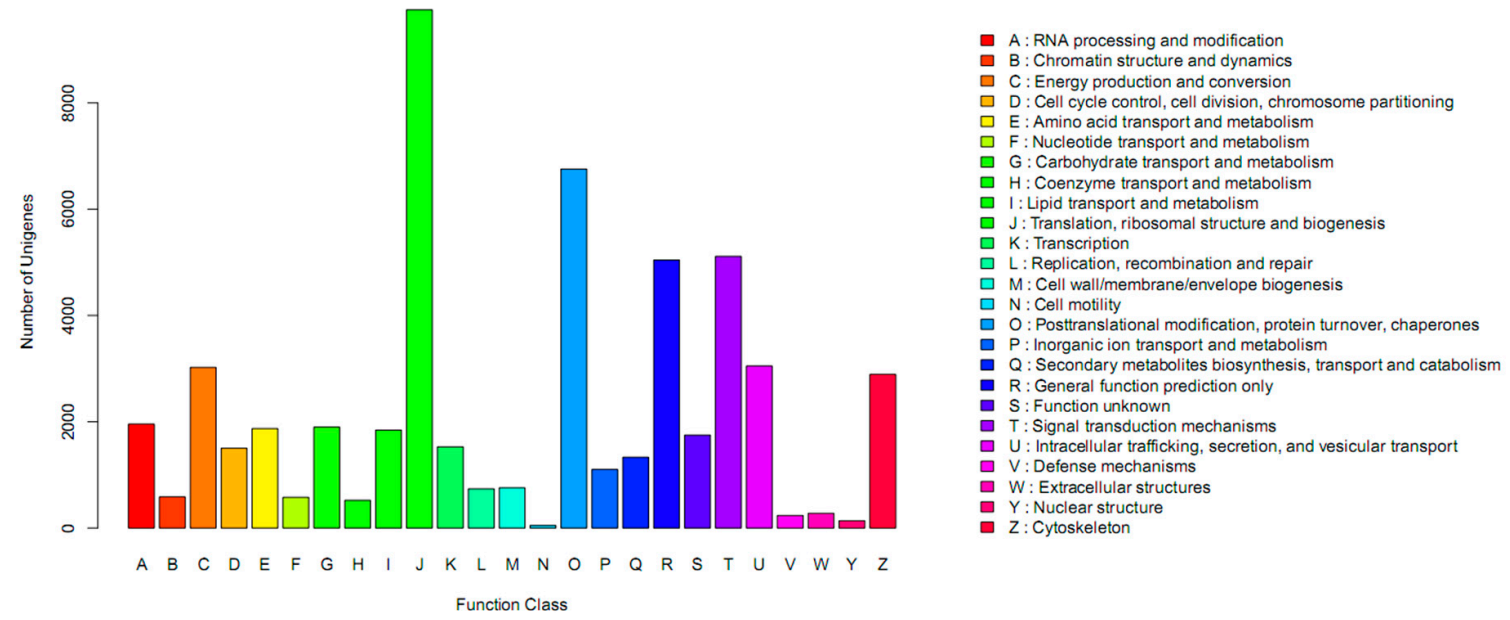

Figure 3. The GO classification of the assembled transcripts.

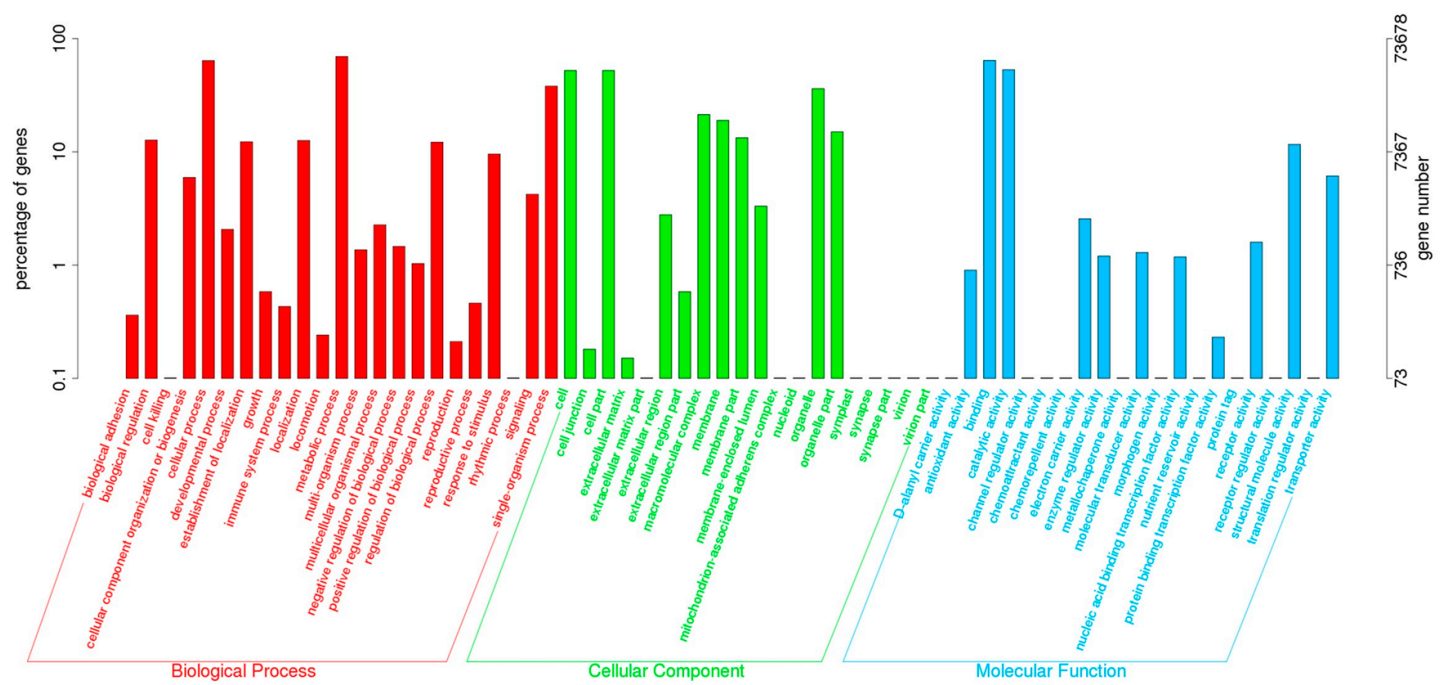

Figure 4. Histogram of KOG classifications.

At the Bonferroni-corrected alpha level of $p \leqslant 0.05,30,772$ up-regulated DEGs were categorized into 804 GO terms (Table S1), and 29,990 DEGs involved in 720 predicted GO terms were significantly down-regulated (Table S2). The Pb-response genes were mapped to the Kyoto Encyclopedia of Genes and Genomes (KEGG) database. Among the enriched pathways of up-regulated genes (Table 3), the KEGG pathway analysis found 13,204 unigenes involved in 52 predicted KEGG 
metabolic pathways. Additionally, 15,666 unigenes were involved in 102 predicted KEGG metabolic pathways among the pathways enriched with down-regulated genes (Table 4). Partial pathways are shown in Tables 3 and 4. Compared to the results in radish [15], the metabolism of xenobiotics by cytochrome P450 [ko00980] and gap junctions [ko04540] were also up- and down-regulated pathways, respectively, under $\mathrm{Pb}$ stress. The results suggest that the same regulatory pathways function in different species under $\mathrm{Pb}$ stress.

Table 3. Enriched pathways containing up-regulated genes under $\mathrm{Pb}$ stress.

\begin{tabular}{|c|c|c|c|c|}
\hline Pathway & Id & $\begin{array}{c}\text { Number of DEGs with } \\
\text { Pathway Annotations }(13,204)\end{array}$ & $\begin{array}{c}\text { Number of Genes with } \\
\text { Pathway Annotations }(14,105)\end{array}$ & $p$-Value \\
\hline $\begin{array}{l}\text { Metabolism of xenobiotics } \\
\text { by cytochrome P450 }\end{array}$ & ko00980 & $134(1.02 \%)$ & $287(2.03 \%)$ & $3.06 \times 10^{-8}$ \\
\hline $\begin{array}{l}\text { Drug metabolism- } \\
\text { cytochrome P450 }\end{array}$ & ko00982 & $122(0.92 \%)$ & $267(1.89 \%)$ & $4.53 \times 10^{-7}$ \\
\hline PPAR signaling pathway & ko03320 & $221(1.67 \%)$ & $548(3.89 \%)$ & $9.40 \times 10^{-7}$ \\
\hline $\begin{array}{l}\text { Protein processing in } \\
\text { endoplasmic reticulum }\end{array}$ & ko04141 & $796(6.03 \%)$ & $2332(16.53 \%)$ & $8.32 \times 10^{-6}$ \\
\hline $\begin{array}{c}\text { Ribosome biogenesis in } \\
\text { eukaryotes }\end{array}$ & ko03008 & $264(2.00 \%)$ & $705(5.00 \%)$ & $5.85 \times 10^{-5}$ \\
\hline RNA polymerase & ko03020 & $122(0.92 \%)$ & $297(2.11 \%)$ & $1.94 \times 10^{-4}$ \\
\hline $\begin{array}{l}\text { Ubiquitin mediated } \\
\text { proteolysis }\end{array}$ & ko04120 & $392(2.97 \%)$ & $1123(7.06 \%)$ & $5.06 \times 10^{-4}$ \\
\hline Proteasome & ko03050 & 313 (2.37\%) & $886(6.28 \%)$ & $9.74 \times 10^{-4}$ \\
\hline $\mathrm{ABC}$ transporters & ko02010 & $152(1.15 \%)$ & 397 (2.81\%) & $9.80 \times 10^{-4}$ \\
\hline Peroxisome & ko04146 & $326(2.47 \%)$ & $929(6.59 \%)$ & $1.11 \times 10^{-3}$ \\
\hline Glutathione metabolism & ko00480 & $248(1.88 \%)$ & $697(4.94 \%)$ & $2.38 \times 10^{-3}$ \\
\hline $\begin{array}{l}\text { Alanine, aspartate and } \\
\text { glutamate metabolism }\end{array}$ & ko00250 & $210(1.59)$ & $594(4.21 \%)$ & $8.02 \times 10^{-3}$ \\
\hline
\end{tabular}

Pathways with $p$-value $\leqslant 0.05$ are significantly enriched in DEGs.

Table 4. Enriched pathways containing down-regulated genes under $\mathrm{Pb}$ stress.

\begin{tabular}{|c|c|c|c|c|}
\hline Pathway & Id & $\begin{array}{c}\text { Number of DEGs with } \\
\text { Pathway Annotations }(13,204)\end{array}$ & $\begin{array}{c}\text { Number of Genes with } \\
\text { Pathway Annotations }(14,105)\end{array}$ & $p$-Value \\
\hline Ribosome & ko03010 & $3988(30.20 \%)$ & $8912(63.18 \%)$ & $8.16 \times 10^{-101}$ \\
\hline $\begin{array}{l}\text { Regulation of actin } \\
\text { cytoskeleton }\end{array}$ & ko04810 & $584(4.42 \%)$ & $1262(8.95 \%)$ & $3.45 \times 10^{-16}$ \\
\hline Gap junction & ko04540 & $269(2.04 \%)$ & $527(3.74 \%)$ & $1.67 \times 10^{-13}$ \\
\hline Calcium signaling pathway & ko04020 & $284(2.15 \%)$ & $661(4.69 \%)$ & $5.06 \times 10^{-4}$ \\
\hline $\begin{array}{l}\text { D-Glutamine and } \\
\text { D-glutamate metabolism }\end{array}$ & ko00471 & $33(0.25 \%)$ & $58(0.41 \%)$ & $8.42 \times 10^{-4}$ \\
\hline
\end{tabular}

Pathways with $p$-value $\leqslant 0.05$ are significantly enriched in DEGs.

\subsection{Validation by Real-Time RT-PCR}

To validate the RNA-Seq technology, the expression levels of 12 candidate DEGs were detected using RT-qPCR (Table 5). The candidate genes selected for validation were associated with metal transporters, transcription factors and chelating compounds. Because AtNRT1.8 can mediate cadmium tolerance [22], we chose one NRT1 family gene, NRT1.2. The transcriptional expression patterns of nine genes (comp152611_c0_seq1, comp100849_c0_seq1, comp123900_c0_seq1, comp160851_c0_seq1, comp142858_c0_seq3, comp130772_c0_seq3, comp1017906_c0_seq1, comp162326 _c2_seq1 and comp423843_c0_seq1) based on RT-qPCR showed an approximate agreement with those of the RNA-Seq-based gene expression patterns (Table 5). However, three genes (comp154333_c1_seq2, comp145580_c0_seq1 and comp147199_c0_seq1) did not show consistent expression levels between RT-qPCR and Illumina sequencing data (Table 5). The differences with respect to ratio and sensitivity between the two techniques may have led to the discrepancies [15]. 
Table 5. Validation of the RNA-Seq expression profiles of selected DEGs using qRT-PCR.

\begin{tabular}{cccc}
\hline Transcript ID & Description & Fold by RNA-Seq & Fold by qPCR \\
\hline comp152611_c0_seq1 & Glutathione $\gamma$-glutamylcysteinyltransferase & 2.64 & 1.89 \\
comp154333_c1_seq2 & Metallothionein-like protein type 2 & 1.90 & 3.68 \\
comp100849_c0_seq1 & WRKY transcription factor 22 & 0.44 & 0.62 \\
comp123900_c0_seq1 & EREBP-like factor & 1.26 & 1.55 \\
comp145580_c0_seq1 & NAC domain-containing protein 90 & 3.58 & 5.22 \\
comp160851_c0_seq1 & Metal transporter Nramp2 & 1.29 & 1.43 \\
comp142858_c0_seq3 & Nitrate transporter 1.2 & 0.12 & 0.05 \\
comp147199_c0_seq1 & Glutathione S-transferase & 6.73 & 8.33 \\
comp130772_c0_seq3 & Ethylene-responsive transcription factor ERF071 & 2.89 & 2.47 \\
comp1017906_c0_seq1 & Zinc finger CCCH domain-containing protein 40 & 9.86 & 8.73 \\
comp162326_c2_seq1 & Myb proto-oncogene protein. plant & 1.27 & 1.38 \\
comp423843_c0_seq1 & Transcription factor bHLH104 & 2.41 & 3.04 \\
\hline
\end{tabular}

\subsection{Analysis of Differential Gene Expression}

In a previous study, no morphological differences were observed between the $\mathrm{Pb}$-stressed seedling and control [23]. To elucidate the expression levels of functional genes and transcription factors under $\mathrm{Pb}$ stress, 3869 significantly changed genes were identified between control and $\mathrm{Pb}$-stressed libraries using the reads per kilobase transcriptome per million mapped reads method. Among these, the number of up- and down-regulated genes was 1850 and 2019, respectively.

Some significant differential gene expressions were analyzed (Table S3). Metallothioneins (MTs) and phytochelatins (PCs) are two types of protein molecules in the biosynthesis of chelating compounds [24]. Class II MTs typically contain four categories (types 1-4) [25], and PCs are non-protein cysteine-rich oligopeptides that are capable of binding to various metals [26]. In the present study, two phytochelatin synthase DEGs, two metallothionein-like protein type 2 DEGs and one metallothionein-like protein type 3 DEG were found in the DEG analysis (Table S3). In A. corniculatum, the expression levels of AcMT genes were also induced by a certain concentration range of $\mathrm{Pb}$ stress compared with the control [27]. Moreover, MT genes were also affected by heavy metals in Iris lacteal [19], Brassica juncea [28] and Brassica campestris [29]. PCs have been demonstrated to be important in heavy metal detoxification and may be used as candidate genes in the phytoremediation of heavy metals [24]; they were found in alfalfa [20], Dianthus carthusianorum [30] and Lotus japonicus [31,32].

Transmembrane metal transporters are assumed to play key roles in heavy metal transport and detoxification [33]. ABC family transporters are the important heavy metal transporters [34]. In our study, the expression levels of $A B C$ transporters were inhibited or induced. Another PDR-type ABC transporter, OsPDR9, is induced by heavy metals in rice roots [35]. AtPDR8, which encodes an $A B C$ transporter, is a cadmium extrusion pump involved in heavy metal resistance [36]. Two zinc transporters (ZIP1 and ZIP3) showed inducible higher expression levels. However, ZIP8 and ZIP9 were down-regulated under $\mathrm{Pb}$ stress (Table S3). In rice, five ZIP transporter genes have been reported [37]. OsZIP1 is strongly inhibited by cadmium, whereas OsZIP3 is inhibited to a lesser extent by calcium [38]. OsZIP4 may be involved in the translocation of zinc [39]. It would be interesting to know the function of the ZIP gene family in Louisiana iris. Another ferrous iron transporter, iron-regulated protein 3 (IRT3), was down-regulated under Pb stress (Table S3). But IRT1 is more highly expressed in Solanum nigrum than in Solanum torvum [20]. In A. thaliana, the IRT1 protein mediates the uptake of heavy metals [40]. In Louisiana iris root, $\mathrm{Pb}$ may be a substrate of the IRT3 protein.

Three metal transporters, a copper transporter, CTR2, a magnesium transporter, MGT and a heavy metal P-type ATPase (HMA5), showed constitutive expression levels. However, their transcript levels significantly increased under Pb-stress conditions (Table S3). In A. thaliana, a five-member family of copper transporters (COPT1-5) was identified, and COPT1 and COPT2 
were down-regulated under copper excess [41]. COPT5 acts as a copper exporter and is involved in the inter-organ reallocation of copper [42]. AtMRS2-11, a putative magnesium transporter, plays an important role in transporting magnesium in the chloroplast membrane system [43]. Moreover, a root-expressed magnesium transporter, MRS2-7, allows $A$. thaliana to grow in low-magnesium environments [44]. For HMA proteins, AtHMA2 is involved in cytoplasmic zinc homeostasis [45]. TcHMA3 is responsible for cadmium tonoplast-localized transportion [46]. TcHMA4 could display cadmium tolerance in the Thlaspi caerulescens cadmium hyperaccumulator [47]. AtHMA5 interacts with ATX1-like copper chaperones and functions in copper compartmentalization and detoxification [48]. High expression levels of CTR2, MGT and HMA5 in Louisiana iris roots may mediate $\mathrm{Pb}$ uptake and transport in plants.

Transcription factors are very important in gene expression regulation [49]. In our results, the transcript expression levels of one $b H L H$, five ERFs and one DREB were affected by $\mathrm{Pb}$ stress, meaning that transcription factors and plant heavy metal stress tolerance have a close relationship. These results had been found in previous studies. AtbHLH29 is involved in controlling iron acquisition [50]. Transgenic plants overexpressing FIT/AtbHLH38 or FIT/AtbHLH39 could exhibit more cadmium tolerance [51]. For the MYBs and ERFs, there were six DEGs, including up- and down-regulated genes, in radish under $\mathrm{Pb}$ stress [15]. DREB genes may play a role in copper tolerance in rice [52], and $L b D R E B$ was found to enhance copper tolerance in transgenic tobacco [53].

$\mathrm{Pb}$ stress can affect the activity of peroxidase, superoxide dismutase, and catalase in plants [54]. One peroxidase, two superoxide dismutases, and one catalase were highly expressed in Louisiana iris roots. The expression patterns were consistent with the physiological results (data not shown).

\section{Experimental Section}

\subsection{Sampling}

In our previous study, Louisiana iris hybrid "Professor Neil" was confirmed to be a tolerant cultivar that can be used for the phytoremediation of contaminated environments [23]. When the plants were under a $200 \mathrm{mg} / \mathrm{L} \mathrm{Pb}\left(\mathrm{NO}_{3}\right)_{2}$ stress treatment, we did not observe any obvious damage. However, visible stress phenotypes (data not shown) can been seen at $400 \mathrm{mg} / \mathrm{L} \mathrm{Pb}\left(\mathrm{NO}_{3}\right)_{2}$. Therefore, $200 \mathrm{mg} / \mathrm{L} \mathrm{Pb}\left(\mathrm{NO}_{3}\right)_{2}$ stress was selected as the treatment. The root is not only the first tissue damaged but also the main tissue bearing the Pb stress. Roots were, therefore, chosen as the most suitable tissue for this experiment. The seedlings were prepared as described by Gu et al. [19]. The $200 \mathrm{mg} / \mathrm{L}$ $\mathrm{Pb}\left(\mathrm{NO}_{3}\right)_{2}$ stress treatment was given to tissue culture seedlings after they reached $10 \mathrm{~cm}$ height in the greenhouse of the Institute of Botany, Jiangsu Province and the Chinese Academy of Sciences (Nanjing, China). Fresh roots of seedlings (three plants per sample) were harvested at two times ( 0 and $24 \mathrm{~h}$ ). Samples were immediately frozen in liquid nitrogen until used.

\section{2. cDNA Library Preparation and Sequencing}

Total RNA was isolated with Trizol reagent (Life Technologies, Inc., Grand Island, NY, USA) following the manufacturer's instructions [5]. Potentially contaminating DNA was eliminated from the total RNA using DNaseI (RNase-free New England Biolabs, Ipswich, MA, USA). RNA quality was confirmed using an Agilent Technologies 2100 Bioanalyzer (Agilent Technologies, Palo Alto, CA, USA), and the RIN values were greater than 7. All of the samples had density absorption ratios A260/A280 between 1.9 and 2.1, and were adjusted to the same RNA concentration. First-strand cDNA was synthesized using the SMART cDNA Synthesis Kit (Clontech Laboratories, Inc., Mountain View, CA, USA). After the second-strand cDNA synthesis reaction, the cDNAs were purified using a QiaQuick PCR extraction kit (Qiagen, Hilden, Germany) and connected with sequencing adapters. The PCR amplifications were selected as templates. The resulting library was sequenced using the Illumina HiSeqTM 2000 platform (Illumina, San Diego, CA, USA). 


\subsection{Transcriptome Sequencing Results Analysis}

Raw sequence processing and de novo assembly were performed following the procedures described by Wang et al. [15]. After the adapters and low quality tags were removed, high-quality clean reads were obtained and assembled using Trinity (trinityrnaseq_r2012-10-05) [55]. Subsequently, unigenes were acquired using the TIGR Gene Indices clustering tools (http://www.tigr.org/tdb/tgi.shtml) [56]. Furthermore, the unigenes were annotated using the BLASTx algorithm against Swiss-Prot, TrEMBL, NCBI, CDD, Pfam and KOG databases with an $E$-value $\leqslant 10^{-5}$. The Blast2Go program was used to analyze GO annotations of unigenes. KOG and KEGG were also used to complement GO functional characterizations and determine the sequence directions of the unigenes.

\subsection{Real-Time RT-PCR}

Total RNA was isolated from young Louisiana iris roots using the RNAiso reagent (TaKaRa, Bio, Tokyo, Japan). RT-qPCR assays were performed on a Mastercycler ${ }^{\circledR}$ ep realplex Real-Time System (Eppendorf, Hamburg, Germany) platform using the SYBR ${ }^{\circledR}$ Premix Ex Taq ${ }^{\mathrm{TM}}$ II (Perfect Real Time) (TaKaRa, Bio, Tokyo, Japan). UBC (Table S4) was used as the reference gene described by Gu et al. [57]. The amplifications were performed as follows: $60 \mathrm{~s}$ at $95{ }^{\circ} \mathrm{C}$ for denaturation, 40 cycles of $15 \mathrm{~s}$ at $95{ }^{\circ} \mathrm{C}, 30 \mathrm{~s}$ at $55^{\circ} \mathrm{C}$, and $30 \mathrm{~s}$ at $72{ }^{\circ} \mathrm{C}$ [58]. Each RT-qPCR reaction was performed in three biological replicates. The $2^{-\Delta \Delta C t}$ method was applied for mean values [59].

\subsection{Analysis of Gene Differential Expression}

To show the differential gene expression levels between control and $\mathrm{Pb}$-stressed roots, we used the reads per kilobase transcriptome per million mapped reads method to calculate the gene expression levels [60]. Significantly, DEGs were identified by estimating the false discovery rate $(p \leqslant 0.001)$ and absolute values of the $\log 2$ Ratio $(\mathrm{Pb} /$ control $) \geqslant 1$.

\section{Conclusions}

In summary, the root transcriptome of Louisiana iris was first characterized by Illumina sequencing. Based on a digital gene expression analysis, many genes that are involved in $\mathrm{Pb}$-stress responses were found. The rich genetic and genomic resources in the transcriptomic data lay a foundation for studying the molecular mechanisms of Louisiana iris tolerance to Pb stress.

Supplementary Materials: Supplementary materials can be found at http://www.mdpi.com/1422-0067/16/ 12/26084/s1.

Acknowledgments: The study was supported by the Qing Lan Project Foundation of Jiangsu Province, the Suzhou Science Foundation of China (Grant Number: SNG201209), the National Natural Science Foundation of China (Grant Number: 31301807), and the Science Foundation of JiangSu (Grant Number: BK20130734).

Author Contributions: Songqing Tian, Chunsun Gu and Suzhen Huang conceived the study and designed the experiments. Chunsun $\mathrm{Gu}$, Liangqin Liu and Yanhai Zhao performed the experiments and Chunsun Gu and Xudong Zhu analysed the data with suggestions by Suzhen Huang, and Chunsun Gu wrote the manuscript.

Conflicts of Interest: The authors declare no conflict of interest.

\section{References}

1. Sanayei, Y.; Ismail, N.; Talebi, S. Determination of heavy metals in Zayandeh Rood river, Isfahan-Iran. World Appl. Sci. J. 2009, 6, 1209-1214.

2. Belyaeva, E.A.; Sokolova, T.V.; Emelyanova, L.V.; Zakharova, I.O. Mitochondrial electron transport chain in heavy metal-induced neurotoxicity: Effects of cadmium, mercury, and copper. Sci. World J. 2012, 136063, 14. [CrossRef] [PubMed]

3. Järup, L. Hazards of heavy metal contamination. Br. Med. Bull. 2003, 68, 167-182. [CrossRef] [PubMed] 
4. Pandey, L.K.; Kumar, D.; Yadav, A.; Rai, J.; Gaur, J. Morphological abnormalities in periphytic diatoms as a tool for biomonitoring of heavy metal pollution in a river. Ecol. Indic. 2014, 36, 272-279. [CrossRef]

5. Ballerini, E.; Mockaitis, K.; Arnold, M. Transcriptome sequencing and phylogenetic analysis of floral and leaf MIKC ${ }^{C}$ MADS-box and R2R3 MYB transcription factors from the monocot Iris fulva. Gene 2013, 531, 337-346. [CrossRef] [PubMed]

6. Van Zandt, P.; Mopper, S. Delayed and carryover effects of salinity on flowering in Iris hexagona (Iridaceae). Am. J. Bot. 2002, 89, 1847-1851. [CrossRef] [PubMed]

7. Nagalakshmi, U.; Wang, Z.; Waern, K.; Shou, C.; Raha, D.; Gerstein, M.; Snyder, M. The transcriptional landscape of the yeast genome defined by RNA sequencing. Science 2008, 320, 1344-1349. [CrossRef] [PubMed]

8. Fan, X.; Wang, J.; Yang, N.; Dong, Y.; Liu, L.; Wang, F.; Wang, N.; Chen, H.; Liu, W.; Sun, Y. Gene expression profiling of soybean leaves and roots under salt, saline-alkali and drought stress by high-throughput Illumina sequencing. Gene 2013, 512, 392-402. [CrossRef] [PubMed]

9. Shen, Y.; Zhang, Y.; Chen, J.; Lin, H.; Zhao, M.; Peng, H.; Liu, L.; Yuan, G.; Zhang, S.; Zhang, Z. Genome expression profile analysis reveals important transcripts in maize roots responding to the stress of heavy metal Pb. Physiol. Plant. 2013, 147, 270-282. [CrossRef] [PubMed]

10. Wang, G.; Zhu, Q.; Meng, Q.; Wu, C. Transcript profiling during salt stress of young cotton (Gossypium hirsutum) seedlings via Solexa sequencing. Acta Physiol. Plant. 2012, 34, 107-115. [CrossRef]

11. Wang, X.; Liu, Y.; Jia, Y.; Gu, H.; Ma, H.; Yu, T.; Zhang, H.; Chen, Q.; Ma, L.; Gu, A. Transcriptional responses to drought stress in root and leaf of chickpea seedling. Mol. Biol. Rep. 2012, 39, 8147-8158. [CrossRef] [PubMed]

12. Yu, S.; Zhang, F.; Yu, Y.; Zhang, D.; Zhao, X.; Wang, W. Transcriptome profiling of dehydration stress in the Chinese cabbage (Brassica rapa L. ssp. pekinensis) by tag sequencing. Plant Mol. Biol. Rep. 2012, 30, 17-28. [CrossRef]

13. Nachappa, P.; Levy, J.; Tamborindeguy, C. Transcriptome analyses of Bactericera cockerelli adults in response to "Candidatus Liberibacter solanacearum" infection. Mol. Genet. Genom. 2012, 287, 803-817. [CrossRef] [PubMed]

14. Zhou, Y.; Gao, F.; Liu, R.; Feng, J.; Li, H. De novo sequencing and analysis of root transcriptome using 454 pyrosequencing to discover putative genes associated with drought tolerance in Ammopiptanthus mongolicus. BMC Genom. 2012, 13, 266. [CrossRef] [PubMed]

15. Wang, Y.; Xu, L.; Chen, Y.; Shen, H.; Gong, Y.; Limera, C.; Liu, L. Transcriptome profiling of radish (Raphanus sativus L.) root and identification of genes involved in response to Lead ( $\mathrm{Pb}$ ) stress with next generation sequencing. PLoS ONE 2013, 8, e66539. [CrossRef] [PubMed]

16. Liu, T.; Liu, S.; Guan, H.; Ma, L.; Chen, Z.; Gu, H.; Qu, L. Transcriptional profiling of Arabidopsis seedlings in response to heavy metal lead $(\mathrm{Pb})$. Environ. Exp. Bot. 2009, 67, 377-386. [CrossRef]

17. Zhou, Y.; Huang, S.; Yu, S.; Gu, J.; Zhao, J.; Han, Y.; Fu, J. The physiological response and sub-cellular localization of lead and cadmium in Iris pseudacorus L. Ecotoxicology 2010, 19, 69-76. [CrossRef] [PubMed]

18. Han, Y.; Huang, S.; Gu, J.; Qiu, S.; Chen, J. Tolerance and accumulation of lead by species of Iris L. Ecotoxicology 2008, 17, 853-859. [CrossRef] [PubMed]

19. Gu, C.; Liu, L.; Zhao, Y.; Deng, Y.; Zhu, X.; Huang, S. Overexpression of Iris. lactea var. chinensis metallothionein 1lMT2a enhances cadmium tolerance in Arabidopsis thaliana. Ecotoxicol. Environ. Saf. 2014, 105, 22-28. [PubMed]

20. Xu, J.; Sun, J.; Du, L.; Liu, X. Comparative transcriptome analysis of cadmium responses in Solanum nigrum and Solanum torvum. New Phytol. 2012, 196, 110-124. [CrossRef] [PubMed]

21. Amemiya, Y.; Usami, T.; Okazaki, R.; Katori, M.; Uematsu, S. A new Phytophthora sp. causing basal rot on Japanese Iris. Phytopathology 2011, 101, S6.

22. Li, J.; Fu, Y.; Pike, S.M.; Bao, J.; Tian, W.; Zhang, Y.; Chen, C.; Zhang, Y.; Li, H.; Huang, J. The Arabidopsis nitrate transporter NRT1.8 functions in nitrate removal from the xylem sap and mediates cadmium tolerance. Plant Cell 2010, 22, 1633-1646. [CrossRef] [PubMed]

23. Zhu, X.; Tian, S.; Huang, S.; Yuan, H. Effects of $\mathrm{Pb}$ on growth and subcellular structure of "Louisiana iris", and its localization in the plant. Fresenius Environ. Bull. 2014, 23, 2395-2400. 
24. Liu, Z.; Gu, C.; Chen, F.; Yang, D.; Wu, K.; Chen, S.; Jiang, J.; Zhang, Z. Heterologous expression of a Nelumbo nucifera phytochelatin synthase gene enhances cadmium tolerance in Arabidopsis thaliana. Appl. Biochem. Biotechnol. 2012, 166, 722-734. [CrossRef] [PubMed]

25. Xia, Y.; Qi, Y.; Yuan, Y.; Wang, G.; Cui, J.; Chen, Y.; Zhang, H.; Shen, Z. Overexpression of Elsholtzia haichowensis metallothionein1 (EhMT1) in tobacco plants enhances copper tolerance and accumulation in root cytoplasm and decreases hydrogen peroxide production. J. Hazard. Mater. 2012, 233-234, 65-71.

26. Gupta, D.; Vandenhove, H.; Inouhe, M. Role of phytochelatins in heavy metal stress and detoxification mechanisms in plants. In Heavy Metal Stress in Plants; Springer: Berlin, Heidelberg, 2013; pp. 73-94.

27. Yi, Y.; Atagana, H.; Liu, J.; Wu, W.; Wu, S. cDNA sequence encoding metallothionein protein from Aegiceras corniculatum and its gene expression induced by $\mathrm{Pb}^{2+}$ and $\mathrm{Cd}^{2+}$ stresses. Environ. Monit. Assess. 2013, 185, 10201-10208.

28. An, Z.; Li, C.; Zu, Y.; Du, Y.; Wachter, A.; Gromes, R.; Rausch, T. Expression of BjMT2, a metallothionein 2 from Brassica juncea, increases copper and cadmium tolerance in Escherichia coli and Arabidopsis thaliana, but inhibits root elongation in Arabidopsis thaliana seedlings. J. Exp. Bot. 2006, 57, 3575-3582.

29. Lv, Y.; Deng, X.; Quan, L.; Xia, Y.; Shen, Z. Metallothioneins BcMT1 and BcMT2 from Brassica campestris enhance tolerance to cadmium and copper and decrease production of reactive oxygen species in Arabidopsis thaliana. Plant Soil 2012, 367, 507-519. [CrossRef]

30. Xu, J.; Zhu, Y.; Ge, Q.; Li, Y.; Sun, J.; Zhang, Y.; Liu, X. Comparative physiological responses of Solanum nigrum and Solanum torvum to cadmium stress. New Phytol. 2012, 196, 125-138. [CrossRef] [PubMed]

31. Ramos, J.; Naya, L.; Gay, M.; Abian, J.; Becana, M. Functional characterization of an unusual phytochelatin synthase, LjPCS3, of Lotus japonicus. Plant Physiol. 2008, 148, 536-545. [CrossRef] [PubMed]

32. Ramos, J.; Clemente, M.R.; Naya, L.; Loscos, J.; Perez-Rontome, C.; Sato, S.; Tabata, S.; Becana, M. Phytochelatin synthases of the model legume Lotus japonicus. A small multigene family with differential response to cadmium and alternatively spliced variants. Plant Physiol. 2007, 143, 1110. [CrossRef] [PubMed]

33. Satoh-Nagasawa, N.; Mori, M.; Nakazawa, N.; Kawamoto, T.; Nagato, Y.; Sakurai, K.; Takahashi, H.; Watanabe, A.; Akagi, H. Mutations in rice (Oryza sativa) heavy metal ATPase 2 (OsHMA2) restrict the translocation of zinc and cadmium. Plant Cell Physiol. 2012, 53, 213-224. [CrossRef] [PubMed]

34. Kazemi-Dinan, A.; Thomaschky, S.; Stein, R.J.; Krämer, U.; Müller, C. Zinc and cadmium hyperaccumulation act as deterrents towards specialist herbivores and impede the performance of a generalist herbivore. New Phytol. 2014, 202, 628-639.

35. Moons, A. Ospdr9, which encodes a PDR-type ABC transporter, is induced by heavy metals, hypoxic stress and redox perturbations in rice roots. FEBS Lett. 2003, 553, 370-376. [CrossRef]

36. Kim, D.Y.; Bovet, L.; Maeshima, M.; Martinoia, E.; Lee, Y. The ABC transporter AtPDR8 is a cadmium extrusion pump conferring heavy metal resistance. Plant J. 2007, 50, 207-218. [CrossRef] [PubMed]

37. Liu, J.; Ma, J.; He, C.; Li, X.; Zhang, W.; Xu, F.; Lin, Y.; Wang, L. Inhibition of cadmium ion uptake in rice (Oryza sativa) cells by a wall-bound form of silicon. New Phytol. 2013, 200, 691-699. [CrossRef] [PubMed]

38. Ramesh, S.A.; Shin, R.; Eide, D.J.; Schachtman, D.P. Differential metal selectivity and gene expression of two zinc transporters from rice. Plant Physiol. 2003, 133, 126-134. [CrossRef] [PubMed]

39. Ishimaru, Y.; Masuda, H.; Suzuki, M.; Bashi, K.; Takahashi, M.; Nakanishi, H.; Mori, S.; Nishizawa, N.K. Overexpression of the OsZIP4 zinc transporter confers disarrangement of zinc distribution in rice plants. J. Exp. Bot. 2007, 58, 2909-2915. [CrossRef] [PubMed]

40. Korshunova, Y.; Eide, D.; Clark, W.; Guerinot, M.; Pakrasi, H. The IRT1 protein from Arabidopsis thaliana is a metal transporter with a broad substrate range. Plant Mol. Biol. 1999, 40, 37-44.

41. Sancenón, V.; Puig, S.; Mira, H.; Thiele, D.J.; Peñarrubia, L. Identification of a copper transporter family in Arabidopsis thaliana. Plant Mol. Biol. 2003, 51, 577-587. [CrossRef] [PubMed]

42. Klaumann, S.; Nickolaus, S.D.; Fürst, S.H.; Starck, S.; Schneider, S.; Ekkehard Neuhaus, H.; Trentmann, O. The tonoplast copper transporter COPT5 acts as an exporter and is required for interorgan allocation of copper in Arabidopsis thaliana. New Phytol. 2011, 192, 393-404. [CrossRef] [PubMed]

43. Drummond, R.; Tutone, A.; Li, Y.; Gardner, R. A putative magnesium transporter AtMRS2-11 is localized to the plant chloroplast envelope membrane system. Plant Sci. 2006, 170, 78-89. [CrossRef]

44. Gebert, M.; Meschenmoser, K.; Svidová, S.; Weghuber, J.; Schweyen, R.; Eifler, K.; Lenz, H.; Weyand, K.; Knoop, V. A root-expressed magnesium transporter of the MRS2/MGT gene family in Arabidopsis thaliana allows for growth in low- $\mathrm{Mg}^{2+}$ environments. Plant Cell 2009, 21, 4018-4030. [CrossRef] [PubMed] 
45. Eren, E.; Argüello, J.M. Arabidopsis HMA2, a divalent heavy metal-transporting PIB-type ATPase, is involved in cytoplasmic $\mathrm{Zn}^{2+}$ homeostasis. Plant Physiol. 2004, 136, 3712-3723. [CrossRef] [PubMed]

46. Ueno, D.; Milner, M.J.; Yamaji, N.; Yokosho, K.; Koyama, E.; Clemencia Zambrano, M.; Kaskie, M.; Ebbs, S.; Kochian, L.; Ma, J. Elevated expression of TcHMA3 plays a key role in the extreme Cd tolerance in a Cd-hyperaccumulating ecotype of Thlaspi caerulescens. Plant J. 2011, 66, 852-862. [CrossRef] [PubMed]

47. Bernard, C.; Roosens, N.; Czernic, P.; Lebrun, M.; Verbruggen, N. A novel CPx-ATPase from the cadmium hyperaccumulator Thlaspi caerulescens. FEBS Lett. 2004, 569, 140-148. [CrossRef] [PubMed]

48. Andrés-Colás, N.; Sancenón, V.; Rodríguez-Navarro, S.; Mayo, S.; Thiele, D.; Ecker, J.; Puig, S.; Peñarrubia, L. The Arabidopsis heavy metal P-type ATPase HMA5 interacts with metallochaperones and functions in copper detoxification of roots. Plant J. 2006, 45, 225-236. [CrossRef] [PubMed]

49. Ganesan, G.; Sankararamasubramanian, H.; Harikrishnan, M.; Ashwin, G.; Parida, A. A MYB transcription factor from the grey mangrove is induced by stress and confers $\mathrm{NaCl}$ tolerance in tobacco. J. Exp. Bot. 2012, 63, 4549-4561. [CrossRef] [PubMed]

50. Yuan, Y.; Juan, Z.; Wang, D.; Ling, H. AtbHLH29 of Arabidopsis thaliana is a functional ortholog of tomato FER involved in controlling iron acquisition in strategy I plants. Cell Res. 2005, 15, 613-621. [CrossRef] [PubMed]

51. Wu, H.; Chen, C.; Du, J.; Liu, H.; Cui, Y.; Zhang, Y.; He, Y.; Wang, Y.; Chu, C.; Feng, Z. Co-Overexpression FIT with AtbHLH38 or AtbHLH39 in Arabidopsis-enhanced cadmium tolerance via increased cadmium sequestration in roots and improved iron homeostasis of shoots. Plant Physiol. 2012, 158, 790-800. [CrossRef] [PubMed]

52. Sudo, E.; Itouga, M.; Yoshida-Hatanaka, K.; Ono, Y.; Sakakibara, H. Gene expression and sensitivity in response to copper stress in rice leaves. J. Exp. Bot. 2008, 59, 3465-3474. [CrossRef] [PubMed]

53. Ban, Q.; Liu, G.; Wang, Y. A DREB gene from Limonium bicolor mediates molecular and physiological responses to copper stress in transgenic tobacco. J. Plant Physiol. 2011, 168, 449-458. [CrossRef] [PubMed]

54. Cao, Y.; Huang, R.; Cao, Z. Effects of Pb stress on the physiological and biochemical traits of maize. J. Maize Sci. 2004, 13, 61-64.

55. Grabherr, M.; Haas, B.; Yassour, M.; Levin, J.; Thompson, D.; Amit, I.; Adiconis, X.; Fan, L.; Raychowdhury, R.; Zeng, Q. Full-length transcriptome assembly from RNA-Seq data without a reference genome. Nat. Biotechnol. 2011, 29, 644-652. [CrossRef] [PubMed]

56. Pertea, G.; Huang, X.; Liang, F.; Antonescu, V.; Sultana, R.; Karamycheva, S.; Lee, Y.; White, J.; Cheung, F.; Parvizi, B. TIGR Gene Indices clustering tools (TGICL): A software system for fast clustering of large EST datasets. Bioinformatics 2003, 19, 651-652. [CrossRef] [PubMed]

57. Gu, C.; Liu, L.; Xu, C.; Zhao, Y.; Zhu, X.; Huang, S. Reference gene selection for quantitative real-time RT-PCR normalization in Iris lactea var. chinensis roots under cadmium, lead, and salt stress conditions. Sci. World J. 2014, 532713, 7.

58. Gu, C.; Liu, L.; Deng, Y.; Zhu, X.; Lu, X.; Huang, S. Validation of reference genes for RT-qPCR normalization in Iris. lactea var. chinensis leaves under different experimental conditions. Sci. Hortic.-Amsterdam 2014, 175, 144-149.

59. Gu, C.; Zhang, X.; Jiang, J.; Guan, Z.; Zhao, S.; Fang, W.; Liao, Y.; Chen, S.; Chen, F. Chrysanthemum CmNAR2 interacts with CmNRT2 in the control of nitrate uptake. Sci. Rep. 2014, 4, 5833. [CrossRef] [PubMed]

60. Mortazavi, A.; Williams, B.; McCue, K.; Schaeffer, L.; Wold, B. Mapping and quantifying mammalian transcriptomes by RNA-Seq. Nat. Methods 2008, 5, 621-628. [CrossRef] [PubMed]

(C) 2015 by the authors; licensee MDPI, Basel, Switzerland. This article is an open access article distributed under the terms and conditions of the Creative Commons by Attribution (CC-BY) license (http://creativecommons.org/licenses/by/4.0/). 